\title{
Invasive breast cancer trials
}

\author{
R. Rampaul, R. Pillarisetti \\ Professorial Unit of Surgery, City Hospital, Nottingham, UK.
}

\section{Danish Breast Cancer Group Protocol 82TM: randomized trial comparing breast- preserving therapy with mastectomy in mammary carcinoma}

\section{Coordinating group: Danish Breast Cancer Cooperative Group}

Study Chair/Coordinator: M. Blichert-Toft

Objective: A randomized trial to compare breast conservation therapy with mastectomy in stage I-IIIA breast carcinomas.

\section{Summary}

\section{Accrual}

- Accrual total: 905

- Accrual period: 1983-1989.

\section{Inclusion}

Patients having:

- Primary operable breast carcinoma

- Age below 70 years

- Probability of satisfactory cosmetic outcome by excision of the tumour-bearing breast

- Tumour confined to one breast - no signs of multicentricity by palpation or mammography

- No evidence of disseminated disease by chest radiography and bone scintigraphy.

\section{Exclusion}

Paget's disease of the nipple, inflammatory cancer of the breast, history of previous malignancy.

Correspondence to: Raj Rampaul, Professorial Unit of Surgery, City Hospital, Hucknall Road, Nottingham NG5 1PB, UK. E-mail: rajendra. rampaul@nottingham.ac.uk; Tel: +44 115823 1879; Fax: +44 1158231881

\section{Treatment}

Patients were randomized to mastectomy or breastconserving therapy (BCT) consisting of complete tumour excision, axillary dissection and radiation treatment.

Seventy-eight per cent of patients accepted the procedure chosen for them by randomization, leaving (after all other protocol violations and other exclusions are accounted for) two groups: 619 patients for whom treatments had been randomly allocated and 136 who had chosen their treatment.

In the BCT arm, treatment consisted of removal of the tumour-bearing part of the breast with enough normal tissue to ensure tumour-free margins at gross examination. All BCT patients were referred to radiotherapy to begin within 2-4 weeks after surgery. The target volume involved the whole breast. Regional lymph nodes were included only in high-risk patients. The dose was 50 Gy in 25 fractions over 5 weeks plus a boost to the tumour bed.

Mastectomy consisted of removal of the entire breast through a transverse incision plus dissection of low- and mid-axilla.

\section{Follow-up}

Patients were followed in six oncological centres in accordance with the protocol. Follow-up consisted of check-ups every 3 months for the first years, every 6 months for the next 4 years, and once a year thereafter.

Primary end point

Survival, disease-free survival (DFS).

Secondary end points

Cosmetic outcome. 


\section{Findings}

No difference in recurrence-free survival or overall survival was observed. At the end of 3 years, of the group which had been randomized for treatment, DFS rates were $80 \%$ for BCT group and $76 \%$ for the mastectomy group. For the non-randomized patients, the recurrence rate was $8 \%$ in the BCT group and $5 \%$ in the mastectomy group.

For the cosmetic outcome, 63 patients treated in one centre were followed up for 3 years. The patient's own opinions and the views of the oncologist who conducted the follow-up were considered in making the assessment. The results show that patients expressed higher satisfaction levels than the oncologists.

\section{Update of the study}

Follow-up

6 years (Cosmetic results): 266 recurrence-free patients were called in after 6.6 years to assess the impact of surgical and radiation treatment upon the cosmetic and functional outcome after breast conservation. Seventy-three per cent responded that the cosmetic result was 'excellent' or 'good'. Breast fibrosis, skin telangicetasia and breast retraction were associated with less satisfaction. A univariate analysis found that treatment with a direct anterior electron field produced more morbidity and reduced cosmetic outcomes compared to tangential photon treatment.

The recurrence rate at 6 years was $18 \%$ : 80 patients in the BCT group and 83 patients in the mastectomy group. The probability of recurrence-free survival was $70 \%$ in the BCT group vs. $66 \%$ in the mastectomy arm (95\% confidence interval).

The overall survival probability rates were $79 \%$ in the BCT arm vs. $82 \%$ in the mastectomy arm. This result showed no significant difference in overall survival between groups $(P>0.05)$.

\section{Further reading}

1. Blichert-Toft M, Brincker $\mathrm{H}$, Andersen JA, Andersen KW, Axelsson CK, Ouridsen HT, Dombernowsky P, Overgaard M, Gadeberg C, Knudsen G, et al. A Danish randomized trial comparing breast-preserving therapy with mastectomy in mammary carcinoma. Preliminary results. Acta Oncol 1988; 27(6A): 671-677.

2. Blichert-Toft $M$, Rose $C$, Andersen JA, Overgaard $M$, Axelsson CK, Andersen KW, Mouridsen HT. Danish randomized trial comparing breast conservation therapy with mastectomy: six years of life-table analysis. Danish Breast Cancer Cooperative Group. Natl Cancer Inst Monogr 1992; (11): 19-25.

3. Johansen J, Overgaard J, Rose C, Engelholm SA, Gadeberg CC, Kjaer M, Kamby C, Juul-Christensen J, Blichert-Toft M, Overgaard M. Danish Breast Cancer Cooperative Group (DBCG) and the DBCG Radiotherapy
Committee. Cosmetic outcome and breast morbidity in breast-conserving treatment - results from the Danish DBCG-82TM national randomized trial in breast cancer. Acta Oncol 2002; 41(4): 369-380.

4. Johansen J, Overgaard J, Blichert-Toft M, Overgaard M. Treatment of morbidity associated with the management of the axilla in breast-conserving therapy. Acta Oncol 2000; 39(3): 349-354.

5. Overgaard $M$, Christensen JJ, Johansen $H$, NyboRasmussen A, Rose C, van der Kooy P, Panduro J, Laursen F, Kjaer M, Sorensen NE, et al. Evaluation of radiotherapy in high-risk breast cancer patients: report from the Danish Breast Cancer Cooperative Group (DBCG 82) Trial. Int J Radiat Oncol Biol Phys 1990; 19(5): 1121-1124.

6. van Tienhoven G, Voogd AC, Peterse JL, Nielsen M, Andersen KW, Mignolet F, Sylvester R, Fentiman IS, van der Schueren E, van Zijl K, Blichert-Toft M, Bartelink H, van Dongen JA. Prognosis after treatment for loco-regional recurrence after mastectomy or breast conserving therapy in two randomised trials (EORTC 10801 and DBCG-82TM). EORTC Breast Cancer Cooperative Group and the Danish Breast Cancer Cooperative Group. Eur J Cancer 1999; 35(1): 32-38.

7. Voogd AC, Nielsen $M$, Peterse JL, Blichert-Toft $M$, Bartelink H, Overgaard M, van Tienhoven G, Andersen KW, Sylvester RJ, van Dongen JA for the Danish Breast Cancer Co-operative Group and the Breast Cancer Co-operative Group of the European Organization for Research and Treatment of Cancer. Differences in risk factors for local and distant recurrence after breast-conserving therapy or masectomy for Stage I and II breast cancer: pooled results of two large European randomized trials. J Clin Oncol 2001; 19(6): 1688-1697.

8. [No authors listed] [A randomized study of tumor resection versus mastectomy in breast cancer. 2.6-year results of the DBCG-82TM (Danish Breast Cancer Cooperative Group) protocol]. Ugeskr Laeger 1991; 153(33): 2272-2276 (Danish).

\section{EORTC Trial 10801: breast conservation compared with mastectomy in tumour, node, metastasis (TNM) stage I and II breast cancer}

Coordinating Group: European Organization for Research and Treatment of Cancer (EORTC) Study Chair/Coordinator: J. A. van Dongen Objective: To compare radical mastectomy (RM) with BCT in stage I and II breast cancer patients with tumours up to $5 \mathrm{~cm}$.

\section{Summary}

\section{Accrual}

- Accrual total: 902 patients

- Accrual period: 1980-1986.

\section{Inclusion}

902 patients, 734 of whom were TNM stage II patients. 
Patients with microscopically incomplete excision of the tumour were included.

\section{Exclusion}

Patients 71 years or older, patients with a Karnofsky index below $80 \%$, patients with tumours fixed to the muscles, or with other questionable operability, with multicentric tumours and with large tumours in small breasts were excluded.

Patients with a previous history of other malignancies other than basal cell carcinoma of the skin and in situ carcinoma of the cervix uteri, those unable to conform to the strict follow-up and those judged emotionally or psychologically unfit to undergo BCT were excluded.

\section{Treatment}

Patients were randomized to either RM or BCT, comprising lumpectomy with attempted margin of $1 \mathrm{~cm}$ of healthy tissue and complete axillary clearance, usually by a separate incision, followed by radiotherapy directed to the breast (50 Gy in 5 weeks) followed by an additional booster dose of $25 \mathrm{~Gy}$ directed to the lumpectomy site.

Quality of life (QoL) evaluation: To evaluate QoL issues, a brief QoL questionnaire was included in the trial which consisted of two multi-item scales (body image and fear of recurrence) and two single items (satisfaction with treatment and cosmetic result). A cosmetic evaluation of the breast after surgery was also performed.

\section{Follow-up}

8 years.

\section{Primary end point}

Primary endpoints were survival, local control, time to distant metastasis and QoL.

\section{Secondary end points}

Cosmetic outcome for patient.

\section{Findings}

After 6 years, overall survival and local recurrence rates did not differ significantly between patients receiving the different treatments.

At 8 years, survival was $73 \%$ after RM and $71 \%$ after BCT, with recurrence rates of $9 \%$ and $15 \%$, respectively. No significant difference exists between the groups.

In the mastectomy group, tumour size did not affect local relapse, but in the BCT group, local recurrence rated were higher for those having tumours of $2-5 \mathrm{~cm}$ $(17 \%)$ than for smaller tumours $(8 \%)(P=0.01)$. However, this significance can be partially explained by completeness of excision, and can be reduced by adjuvant treatment.

Both the mastectomy and BCT arms showed significant effect of node status on relapse rates. Together, the two arms showing node-positivity is a significant factor in recurrence $(P=0.008)$.

QoL findings: At 2-year post-surgery, treatment comparison of the QoL scored was conducted using a Wilcoxon rank-sum test. The result showed significant benefit in body image and satisfaction with treatment in the BCT group compared to the mastectomy group, and no significant difference in fear of recurrence was observed between the two groups.

\section{Update of the study}

\section{Follow-up}

10 years: No difference in overall survival rates between groups, which was $66.1 \%$ for those receiving mastectomy and 65.2 for those receiving BCT $(P=0.11)$. Adjustment for clinical tumour size (smaller or larger than $2 \mathrm{~cm}$ ) pathologic axillary lymph node status and age in a Cox proportional hazards model did not reveal a difference between the two treatment groups.

No difference in time to distant metastases was found, the rate being $66.3 \%$ for patients assigned to mastectomy and $60.5 \%$ for those given BCT $(P=0.24)$.

The rates of loco-regional recurrence did differ significantly according to treatment. Patients who received mastectomy had a loco-regional recurrence rate of $9.8 \%$, while those receiving $\mathrm{BCT}$ had a rate of $11.8(P=0.0097)$. A log-rank test showed that the recurrence rate was significantly higher for those patients assigned to BCT, 1.64 times higher after the figures were adjusted for tumour size, pathologic lymph node status and patient age in a Cox model.

\section{Interpretation}

No difference was found in overall survival between modified RM and BCT for patients with tumours of $<5 \mathrm{~cm}$.

\section{Further reading}

1. Bartelink H. Radiotherapy in the management of early breast cancer: a review. Eur J Cancer Clin Oncol 1988; 24(1): 77-82 (review).

2. Borger $\mathrm{JH}$. The impact of surgical and pathological findings on radiotherapy of early breast cancer. Radiother Oncol 1991; 22(4): 230-236 (review). 
3. Curran D, van Dongen JP, Aaronson NK, Kiebert G, Fentiman IS, Mignolet F, Bartelink H. Quality of life of earlystage breast cancer patients treated with radical mastectomy or breast-conserving procedures: results of EORTC Trial 10801. The European Organization for Research and Treatment of Cancer (EORTC), Breast Cancer Co-operative Group (BCCG). Eur J Cancer 1998; 34(3): 307-314.

4. Hooning $M J$, van Dongen JA, Hart AA, Peterse JL, Bruggink ED, Went G. Breast cancer: a study into the value of a historical group as comparative material for new methods of treatment. Eur J Surg Oncol 1992; 18(1): 16-22.

5. Noel G, Mazeron JJ. [Long-term results of a randomized trial comparing breast-conserving therapy with mastectomy: European Organization for Research and Treatment of Cancer 10801 trial] Cancer Radiother 2001; 5(2): 211-212 (French; no abstract available).

6. van Dongen JA, Bartelink H, Fentiman IS, Lerut $T$, Mignolet F, Olthuis G, van der Schueren E, Sylvester R, Tong D, Winter J, et al. Factors influencing local relapse and survival and results of salvage treatment after breastconserving therapy in operable breast cancer: EORTC trial 10801, breast conservation compared with mastectomy in TNM stage I and II breast cancer. Eur J Cancer 1992; 28A(4-5): 801-805.

7. van Dongen JA, Voogd AC, Fentiman IS, Legrand C, Sylvester RJ, Tong D, van der Schueren E, Helle PA, van Zijl K, Bartelink H. Long-term results of a randomized trial comparing breast-conserving therapy with mastectomy: European Organization for Research and Treatment of Cancer 10801 trial. J Natl Cancer Inst 2000; 92(14): 1143-1150.

8. van Dongen JA, Bartelink $H$, Fentiman IS, Lerut $T$, Mignolet F, Olthuis G, van der Schueren E, Sylvester R, Winter J, van Zijl K. Randomized clinical trial to assess the value of breast-conserving therapy in stage I and II breast cancer, EORTC 10801 trial. J Natl Cancer Inst Monogr 1992; (11): 15-18.

9. van Tienhoven G, Voogd AC, Peterse JL, Nielsen M, Andersen KW, Mignolet F, Sylvester R, Fentiman IS, van der Schueren E, van Zijl K, Blichert-Toft M, Bartelink H, van Dongen JA. Prognosis after treatment for loco-regional recurrence after mastectomy or breast conserving therapy in two randomised trials (EORTC 10801 and DBCG-82TM). EORTC Breast Cancer Cooperative Group and the Danish Breast Cancer Cooperative Group. Eur J Cancer 1999; 35(1): 32-38.

10. Voogd, AC, Nielsen $M$, Peterse JL, Blichert-Toft $M$, Bartelink H, Overgaard M, van Tienhoven G, Andersen KW, Sylvester RJ, van Dongen JA for the Danish Breast Cancer Co-operative Group and the Breast Cancer Co-operative Group of the European Organization for Research and Treatment of Cancer. Differences in risk factors for local and distant recurrence after breast-conserving therapy or masectomy for Stage I and II breast cancer: pooled results of two large European randomized trials. J Clin Oncol 2001; 19(6): 1688-1697.

\section{National Cancer Institute's randomized trial comparing mastectomy vs. BCT in the treatment of stage I and II carcinoma of the breast}

Coordinating group: National Cancer Institute
Study Chair/Coordinator: J. A. Jacobson

Objective: To compare mastectomy vs. excisional biopsy (lumpectomy) plus radiation for the treatment of stage I and II breast cancer.

\section{Summary}

Accrual

- Accrual total: 247

- Accrual period: 1979-1987.

\section{Inclusion}

Patients with clinical status T1-3, N0-1, M0.

\section{Exclusion}

Patients with advanced local disease, distant metastases, inflammatory carcinoma, multiple metastases, bilateral breast carcinoma or non-palpable lesions manifested only by nipple discharge or skin rash Paget's disease). Other exclusion criteria were current pregnancy or lactation, history of previous cancer other than non-melanoma skin cancer, or presence of other chronic disease which made patient a poor operative risk.

\section{Treatment}

Patients received either modified RM or lumpectomy. Mastectomy treatment consisted of total mastectomy plus complete axillary dissection of level 1 through 3. No post-operative chest wall irradiation was administered.

Lumpectomy consisted of total gross tumour removal; microscopically free surgical margins were not required. Patients who underwent lumpectomy also had radiation therapy consisting of external beam therapy (4500-5000 cGy at 180 Gy per fraction 5 days a week) with or without supraclavicular nodal irradiation followed by a boost to the tumour bed (1500-2000 cGy).

All patients received a full axillary dissection and all node-positive patients received adjuvant chemotherapy with cyclophosphamide and doxorubicin.

To determine the psychological benefits of BCT, a baseline assessment was carried out prior to randomization, with questionnaires to follow up at 6,12 and 24 months after completion of treatment.

\section{Follow-up}

Minimum follow-up: 18 months; median follow-up: 68 months.

\section{Primary end points}

Overall survival and DFS, distant disease-free survival (DDFS). 
Secondary end points

Psychological benefit of BCT.

\section{Findings}

BCT using lumpectomy and breast irradiation is equivalent to mastectomy in terms of survival and ultimate local control for stage I and II breast cancer.

\section{Update of the study}

Follow-up

5 and 8 years: At 5 years, no differences on overall survival ( $85 \%$ for mastectomy, $89 \%$ for lumpectomy; $\left.P_{2}=0.41\right)$ or DFS (82\% for mastectomy, $72 \%$ for lumpectomy; $P_{2}=0.24$ ) were observed. Patients undergoing lumpectomy plus irradiation had a recurrence rate of $12 \%$ at 5 years and $20 \%$ at 8 years.

At 5 years, for all patients, T stage and nodal status were significant prognostic variables. Patients with $\mathrm{T}_{1}$ and $\mathrm{T}_{2}$ tumours had 5-year disease-free rates of $88 \%$ and $64 \%$, respectively $\left(P_{2}=0.0002\right)$. Nodenegative patients had better survival rates than node-positive patients ( $85 \%$ vs. $\left.65 \% ; P_{2}=0.0001\right)$.

For node-positive patients, DFS rates did not differ according to treatment. For node-negative patients, those in the mastectomy arm had improved DFS compared to those in the lumpectomy group (94\% compared to $76 \% ; P_{2}=0.012$ ). However, this difference can be fully accounted for by the number of breast-only failures in the lumpectomy arm.

At 8 years, the loco-regional failure rates ( 9 in the mastectomy group vs. 16 in radiation group) showed no significant difference $\left(P_{2}=0.18\right)$. Overall survival rates were not significantly different at $85 \%$ vs. $89 \%$.

The psychological aspect of the study showed significant results. The questionnaires showed that, at 6 months, the mastectomy patients reported significantly less control over events in their lives, and showed significant differences from BCDT patients towards body image and body satisfaction. Over time, these results were $P=0.001$ at 6 months, $P=0.019$ at 12 months and $P=0.057$ at 24 months.

10 years: At 10 years, survival was $75 \%$ for patients assigned to mastectomy and $77 \%$ for those assigned to lumpectomy plus radiation. DFS at 10 years was $69 \%$ for patients who underwent mastectomy vs. $72 \%$ for those who underwent lumpectomy plus radiation. The rate of local regional recurrence was $10 \%$ after mastectomy and $5 \%$ after lumpectomy plus radiation after recurrences successfully treated by mastectomy were censored from the analysis. The 10-year followup shows that BCT shows similar results to mastectomy after 10 years.

18 years: At median 18.4 years, there was no detectable difference in survival rates for those who has been assigned to mastectomy (58\%) compared to those who had been assigned to mastectomy plus radiation (54\%) $(P=0.67)$. DFS rates were also similar: $67 \%$ for those who underwent mastectomy compared to $63 \%$ for those who underwent BCT $(P=0.64)$. These results show that at 20 years, there was no detectable difference in overall survival or DFS in patients treated with mastectomy compared to BCT.

\section{Further reading}

1. Jacobson JA, Danforth DN, Cowan KH, d'Angelo T, Steinberg SM, Pierce L, Lippman ME, Lichter AS, Glatstein E, Okunieff $P$. Ten-year results of a comparison of conservation with mastectomy in the treatment of stage I and II breast cancer. N Engl J Med 1995; 332(14): 907-911.

2. Lazovich D, Solomon CC, Thomas DB, Moe RE, White E. Breast conservation therapy in the United States following the 1990 National Institutes of Health Consensus Development Conference on the treatment of patients with early stage invasive breast carcinoma. Cancer 1999; 86(4): 628-637.

3. Lichter AS, Lippman ME, Danforth Jr DN, d'Angelo T, Steinberg SM, deMoss E, MacDonald HD, Reichert CM, Merino M, Swain SM, et al. Mastectomy versus breastconserving therapy in the treatment of stage I and II carcinoma of the breast: a randomized trial at the National Cancer Institute. J Clin Oncol 1992; 10(6): 976-983.

4. Poggi MM, Danforth DN, Sciuto LC, Smith SL, Steinberg SM, Liewehr DJ, Menard C, Lippman ME, Lichter AS, Altemus RM. Eighteen-year results in the treatment of early breast carcinoma with mastectomy versus breast conservation therapy: the National Cancer Institute Randomized Trial. Cancer 2003; 98(4): 697-702.

5. Schain WS, d'Angelo TM, Dunn ME, Lichter AS, Pierce LJ. Mastectomy versus conservative surgery and radiation therapy. Psychosocial consequences. Cancer 1994; 73(4): 1221-1228.

6. Straus K, Lichter A, Lippman M, Danforth D, Swain S, Cowan K, deMoss E, MacDonald H, Steinberg S, d'Angelo T, et al. Results of the National Cancer Institute early breast cancer trial. J Natl Cancer Inst Monogr 1992; (11): 27-32.

7. Straus K, Lichter A, Lippman M, Danforth D, Swain S, Cowan K, deMoss E, MacDonald H, Steinberg S, d'Angelo $\mathrm{T}$, et al. Results of the National Cancer Institute early breast cancer trial. N Eng J Med 1985; 312(11): 664-669.

\section{Comparing RM with quadrantectomy, axillary dissection and radiotherapy in patients with small cancers of the breast (Milan I Trial)}

Coordinating group: National Cancer Institute of Italy

Study Chair/Coordinator: U. Veronesi

Objective: To compare the efficacy of radical (Halsted) mastectomy with that of BCT (consisting of quadrantectomy followed by radiotherapy). 


\section{Summary}

Accrual

- Accrual total: 701

- Accrual period: 1973-1980.

\section{Inclusion}

Patients with tumours measuring $<2 \mathrm{~cm}$ in diameter and with no palpable axillary nodes (T1NOM0).

\section{Exclusion}

Patients older than 70 years or who had a history of cancer.

\section{Treatment}

Patients were randomized to RM or quadrantectomy with axillary dissection and radiotherapy to the ipsilateral residual breast tissue; 349 patients were treated with Halsted mastectomy and 352 with quadrantectomy. The quadrantectomy comprised the entire quadrant of the breast with $\geqslant 2 \mathrm{~cm}$ of normal surrounding breast tissue together with the overlying skin and the corresponding portion of the fascial sheet of the petcoralis major. The radiotherapy consisted of $6000 \mathrm{rad}$ to the residual breast tissue over 5-6 weeks, starting 15 days after the operation. After 1976, patients in both groups who had positive axillary nodes also received adjuvant chemotherapy with cyclophosphamide, methotrexate and fluorouracil. The two groups were comparable in age distribution, size and site of primary tumour, menopausal status and frequency of axillary metastases.

\section{Follow-up}

For the first 10 years, patients were seen every 3 months at clinic and underwent a complete examination including chest and skeletal radiography, liver ultrasonography and mammography every year. Thereafter, patients were seen once a year and underwent routing annual mammography. Other examinations were performed when clinically indicated. The median follow-up was 20 years.

\section{Primary end point \\ Survival and DFS.}

\section{Findings}

Preliminary results in 1981 showed no difference in survival rates between the two groups. Quadrantectomy is a valid alternative to mastectomy in patients with tumours smaller than $2 \mathrm{~cm}$ and with no palpable axillary nodes.

\section{Update of the study}

Follow-up

8 years: The DFS was $77 \%$ for the mastectomy group and $80 \%$ for the quadrantectomy group. The overall survival rates were $83 \%$ for those in the mastectomy group and $85 \%$ for those in the quadrantectomy group. These results uphold the preliminary conclusion that BCT is a valid alternative for patients having tumours of $<2 \mathrm{~cm}$ and without palpable axillary nodes. The results did show that the cumulative probability of survival tends to decrease with increasing tumour size: the 7-year survival rate was $84 \%$ in cases in which lesions measures from 1.6 to $2.0 \mathrm{~cm}$ and $94 \%$ in cases in which the lesions were $<0.05 \mathrm{~cm}$.

20 years: At 20-year follow-up, 30 women in the BCT group had a recurrence in the same breast, compared with 8 in the mastectomy group, giving recurrence rates of $8.8 \%$ compared with $2.3 \%$ $(P<0.001)$. By contrast, there was no significant difference between the two groups in the rates of contralateral breast carcinomas, distant metastases and second primary cancers. The overall death rate from all causes was $41.7 \%$ in the BCT group and $41.2 \%$ in the mastectomy group $(P=1.0)$. The death rates from breast cancer were $26.1 \%$ in the BCT group and $24.3 \%$ in the mastectomy group $(P=0.8)$. These figures confirm the conclusion that the longterm survival rate among women who undergo BCT is the same as for women who undergo RM.

\section{Interpretation}

Results after $25+$ years confirm the initial conclusion that, given the lack of significant difference in survival rates between the two groups, quadrantectomy is a valid alternative to mastectomy in patients with tumours smaller than $2 \mathrm{~cm}$ and with no palpable axillary nodes.

\section{Further reading}

1. Salvadori B, Veronesi U. Conservative methods for breast cancer of small size: the experience of the National Cancer Institute, Milan (1973-1998). Breast 1999; 8(6): 311-314.

2. Veronesi U, Saccozzi R, Del Vecchio M, Banfi A, Clemente C, De Lena M, Gallus G, Greco M, Luini A, Marubini E, Muscolino G, Rilke F, Salvadori B, Zecchini A, Zucali R. Comparing radical mastectomy with quadrantectomy, axillary dissection, and radiotherapy in patients with small cancers of the breast. N Engl J Med 1981; 305(1): 6-11.

3. Veronesi U, Banfi A, Del Vecchio M, Saccozzi R, Clemente C, Greco M, Luini A, Marubini E, Muscolino G, Rilke F, et al. Comparison of Halsted mastectomy with quadrantectomy, axillary dissection, and radiotherapy in early breast 
cancer: long-term results. Eur J Cancer Clin Oncol 1986; 22(9): 1085-1089.

4. Veronesi U, Luini A, Galimberti V, Zurrida S. Conservation approaches for the management of stage I/II carcinoma of the breast: Milan Cancer Institute trials. World $J$ Surg 1994; 18(1): 70-75.

5. Veronesi U, Del Vecchio M, Greco M, Luini A, Muscolino G, Rasponi A, Saccozzi R, Zucali R. Conservative treatment for breast cancer of limited extent. Results of a randomized trial. Isr J Med Sci 1981; 17(9-10): 928--931.

6. Veronesi U, Banfi A, Saccozzi R, Salvadori B, Zucali R, Uslenghi C, Greco M, Luini A, Rilke F, Sultan L. Conservative treatment of breast cancer. A trial in progress at the Cancer Institute of Milan. Cancer 1977; 39(Suppl 6): 2822-2826.

7. Veronesi U, Salvadori B, Luini A, Banfi A, Zucali R, Del Vecchio M, Saccozzi R, Beretta E, Boracchi P, Farante G, et al. Conservative treatment of early breast cancer. Longterm results of 1232 cases treated with quadrantectomy, axillary dissection, and radiotherapy. Ann Surg 1990; 211(3): 250-259.

8. Veronesi U, Cascinelli N, Mariani L, Greco M, Saccozzi R, Luini A, Aguilar M, Marubini E. Twenty-year follow-up of a randomized study comparing breast-conserving surgery with radical mastectomy for early breast cancer. N Engl J Med 2002; 347(16): 1227-1232.

\section{NSABP Protocol B-06: a protocol to compare segmental mastectomy (SM) and axillary dissection with and without radiation of the breast and total mastectomy and axillary dissection}

Coordinating group: National Surgical Adjuvant Breast and Bowel Project (NSABP)

Study Chair/Coordinator: E. R. Fisher

Objective: To determine in patients with or without clinical axillary node involvement who may be amenable to SM whether:

(1) SM and axillary dissection with or without radiation of the breast is equivalent to total mastectomy plus axillary dissection

(2) Cosmetically acceptable preservation of the breast in a subset of patients with primary cancer can be achieved without unfavourably influencing treatment failure and mortality rates as well as morbidity

(3) To obtain evidence to indicate the clinical significance of microscopic multifocal tumour in the breast.

\section{Summary}

Accrual

- Accrual target/total: 2163

- Accrual period: April 8th 1976 to January 1st 1984.
Inclusion

Patients with either negative or positive axillary nodes and tumours $4 \mathrm{~cm}$ or less with no fixation to underlying muscle or chest wall.

\section{Exclusion}

Prior cancer, metastatic disease, Paget's disease, pregnant or breastfeeding.

\section{Treatment}

Patients were randomized to one of the three treatments: total mastectomy, lumpectomy followed by breast irradiation or lumpectomy without radiation. Patients in the lumpectomy group had resection of the tumour plus removal of enough normal tissue to ensure clear margins.

All groups had axillary dissection. Women with positive axillary nodes received adjuvant chemotherapy with melphalan and fluorouracil.

All lumpectomy specimens were examined pathologically to ensure clear margins, with a total mastectomy given if margins were not clear, but these cases were not considered as a treatment failure and continued in the study arm to which they had been randomized.

The patients assigned to the radiotherapy arm were to begin treatment no later than 6 weeks after surgery for patients with negative nodes, and 8 weeks for patients with positive nodes. A total dose of 5000 rad was given at a rate of 200 rad per day, 5 days a week. No supplement boosts were given.

\section{Follow-up}

5 years

\section{Findings}

The results of this randomized trial involving 1843 women followed for 5 years indicate that lumpectomy followed by breast irradiation is appropriate therapy for patients with stage I or II breast cancer (tumour size $\leqslant 4 \mathrm{~cm}$ ), provided that the margins of the resected specimens are free of tumour.

Lumpectomy followed by irradiation resulted in a 5 -year survival rate of $85 \%$, as compared with $76 \%$ for mastectomy, in DDFS rate of $76 \%$ for lumpectomy compared with $72 \%$ for mastectomy, and a DFS rate of $72 \%$ compared with $66 \%$ for mastectomy.

Results were further analysed to correlate the DFS, DDFS and survival (S) of 1157 histologically nodenegative breast cancer patients with the oestrogen and/or progesterone receptor (ER, PR) and with the nuclear or histological grade (NG, HG) of their tumours. All had been treated by surgery without systemic 
adjuvant therapy. The DFS, DDFS and S were significantly greater in patients with ER positive than ER negative tumours. Patients with PR positive tumours had significantly better survival. When combined with ER, PR made no independent contribution to outcome prediction.

At a mean follow-up of 103 months, $9 \%$ of patients had ipsilateral breast tumour recurrence (IBTR) following treatment for stage I and II invasive breast cancer by lumpectomy and local breast irradiation. The features of these IBTR support earlier findings that this recurrence reflects residual cancer. Analysis did show that patient aged $<35$ years to be a significant factor - no link between 32 other pathologic features and IBTR was found. Survival was related to race, nodal status, NR, histology type and IBTR. Survival rates did not differ between patients treated by radiation, lumpectomy or mastectomy.

In 1990, the prognostic significance of erbB-2 protein overexpression was examined; $21 \%$ of samples (out of a 292 sample set) had erbB-2 overexpression. ErbB-2 overexpression was found to have significant prognostic value, with women whose tumours overexpressed erbB-2 having twice the mortality rate of women without detectable erbB-2 expression. In a multivariate analysis, erbB-2 overexpression was found to be the second most predictive independent variable or survival after nodal status.

\section{Update of the study}

\section{Follow-up}

8 years: $90 \%$ of women treated with lumpectomy followed by irradiation remained free of ipsilateral breast tumour, compared with $61 \%$ of those not treated with irradiation $(P=0.001)$. For women with positive axillary nodes, only $6 \%$ of those treated with radiation had a recurrence.

Comparing women who underwent lumpectomy plus radiation to the mastectomy group, the DFS rates (58 \pm 2.6 vs. $59 \pm 2.5 ; P=0.2$ ), the DDFS rates $(65 \pm 2.6$ vs. $64 \pm 2.5 ; P=1.0)$ and the overall survival rates $(71 \pm 2.6$ vs. $76 \pm 2.1 ; P=0.3)$ showed no survival advantage to mastectomy.

Among women who underwent lumpectomy, there was no significant difference between DDFS $(P=0.2)$ or survival $(P=0.3)$ between the radiation and non-irradiated groups, but the non-irradiated group had a greater recurrence rate in the ipsilateral breast.

These findings continue to support lumpectomy in patients with stage I or II breast cancer, and further show that irradiation reduces the probability of local recurrence following lumpectomy.

At 8 years, the findings were retrospectively analysed to identify prognostic discriminants for survival for node-negative invasive breast cancer patients. This sub-analysis looked at 22 pathologic features and 4 clinical features for their prognostic significance. Their assessment in a Cox regression model showed three to be prognostically significant: survival was related to race, NG and histology type.

10 years: At 10 years, the data was retrospectively analysed to look for pathologic and clinical prognostic determinants; 22 pathologic and 5 clinical variables that were observed in 1090 node-negative and 651 node-positive patients were analysed to determine their prognostic value. The results of a multivariate Cox regression model showed better survival in node-negative patients who were Caucasian, who had tubular, mucinous or papillary tumours rather than lobular invasive, classic medullary or not otherwise specified combinations, and for tumours with good rather than poor NG. This led to the conclusion that the prognostic factors for node-negative patients were similar to those reported previously.

12 years: At the 12-year point, no significant differences were found in overall survival, DFS or DDFS between patients who underwent the different treatment types.

For patients with node-negative cancer in all the three treatment arms, significantly or nearly significantly, higher numbers of patients treated with lumpectomy plus irradiation or total mastectomy remained distant disease-free than patients treated with lumpectomy alone. But no difference was found between DFS and DDFS for patients with node-positive cancer.

Comparing the two lumpectomy cohorts, the results showed that recurrence in the ipsilateral breast was significantly less in patients treated with radiation therapy: $35 \%$ vs. $10 \%(P<0.001)$.

15 years: 31 pathologic and 6 clinical features that were observed in a subset of 1039 evaluable patients were assessed as to their value in predicting survival, in predicting IBTR and in predicting the necessity for local breast irradiation after lumpectomy. Results of this analysis showed that (1) IBTR, race, histological tumour type, nodal status, NG and blood vessel invasion affected survival independently; (2) treatment, patient age, NG, presence of intraductal carcinoma and lymphocytic tumour infiltrate predicted IBTR by multivariate analyses and (3) irradiation reduced IBTR from $36 \%$ to $12 \%$ in the data set analysed.

20 years: Using data from 1851 women whose nodal status known, analysis showed that ipsilateral recurrence rate was $14.3 \%$ in women who underwent lumpectomy and irradiation, compared to $39.2 \%$ for women who underwent lumpectomy without irradiation $(P<0.001)$. 
No significant difference occurred between the different treatments (mastectomy, lumpectomy, lumpectomy plus irradiation) with respect to DFS $(P=0.26)$, DDFS $(P=0.34)$ and survival $(P=0.57)$, but radiation therapy was associated with a marginally significant decrease in mortality. The ipsilateral recurrence rate at 20 years was $14.3 \%$ for the lumpectomy plus radiation cohort compared to $39.2 \%$ in the lumpectomy alone cohort $(P<0.001)$.

The 20-year follow-up upholds the conclusions that lumpectomy and irradiation is appropriate therapy for women with breast cancer, provided that the margins of resected specimens are free of tumour.

\section{Further reading}

1. Christian MC, McCabe MS, Korn EL, Abrams JS, Kaplan RS, Friedman MA. The National Cancer Institute audit of the National Surgical Adjuvant Breast and Bowel Project Protocol B-06. N Engl J Med 1995; 333(22): 1469-1474.

2. Deutsch M, Land SR, Begovic M, Wieand HS, Wolmark $\mathrm{N}$, Fisher $\mathrm{B}$. The incidence of lung carcinoma after surgery for breast carcinoma with and without postoperative radiotherapy. Results of National Surgical Adjuvant Breast and Bowel Project (NSABP) clinical trials B-04 and B-06. Cancer 2003; 98(7): 1362-1368.

3. Fisher B, Wickerham DL, Deutsch M, Anderson S, Redmond C, Fisher ER. Breast tumor recurrence following lumpectomy with and without breast irradiation: an overview of recent NSABP findings. Semin Surg Oncol 1992; 8(3): 153-160 (review).

4. Fisher B, Anderson S. Conservative surgery for the management of invasive and noninvasive carcinoma of the breast: NSABP trials. National Surgical Adjuvant Breast and Bowel Project. World J Surg 1994; 18(1): 63-69 (review).

5. Fisher B, Redmond C, Poisson R, Margolese R, Wolmark N, Wickerham L, Fisher E, Deutsch M, Caplan R, Pilch Y, et al. Eight-year results of a randomized clinical trial comparing total mastectomy and lumpectomy with or without irradiation in the treatment of breast cancer. N Engl J Med 1989; 320(13): 822-828.

6. Fisher B, Redmond C. Lumpectomy for breast cancer: an update of the NSABP experience. National Surgical Adjuvant Breast and Bowel Project. J Natl Cancer Inst Monogr 1992; (11): 7-13 (review).

7. Fisher B, Dignam J, Tan-Chiu E, Anderson S, Fisher ER, Wittliff JL, Wolmark N. Prognosis and treatment of patients with breast tumors of one centimeter or less and negative axillary lymph nodes. J Natl Cancer Inst 2001; 93(2): 112-120.

8. Fisher B, Anderson S, Redmond CK, Wolmark N, Wickerham DL, Cronin WM. Reanalysis and results after 12 years of follow-up in a randomized clinical trial comparing total mastectomy with lumpectomy with or without irradiation in the treatment of breast cancer. N Engl J Med 1995; 333(22): 1456-1461.

9. Fisher B, Redmond C, Fisher ER, Caplan R. Relative worth of estrogen or progesterone receptor and pathologic characteristics of differentiation as indicators of prognosis in node negative breast cancer patients: findings from National Surgical Adjuvant Breast and Bowel Project Protocol B-06. J Clin Oncol 1988; 6(7): 1076-1087.
10. Fisher B, Anderson S, Bryant J, Margolese RG, Deutsch M, Fisher ER, Jeong JH, Wolmark N. Twenty-year follow-up of a randomized trial comparing total mastectomy, lumpectomy, and lumpectomy plus irradiation for the treatment of invasive breast cancer. N Engl J Med 2002; 347(16): 1233-1241.

11. Fisher ER, Anderson S, Tan-Chiu E, Fisher B, Eaton L, Wolmark N. Fifteen-year prognostic discriminants for invasive breast carcinoma. National Surgical Adjuvant Breast and Bowel Project Protocol-06. Cancer 2001; 91(Suppl 8): 1679-1687.

12. Fisher ER, Anderson S, Redmond C, Fisher B. Ipsilateral breast tumor recurrence and survival following lumpectomy and irradiation: pathological findings from NSABP protocol B-06. Semin Surg Oncol 1992; 8(3): 161-166.

13. Fisher ER, Redmond C, Fisher B, Bass G. Pathologic findings from the National Surgical Adjuvant Breast and Bowel Projects (NSABP). Prognostic discriminants for 8-year survival for node-negative invasive breast cancer patients. Cancer 1990; 65(Suppl 9): 2121-2128.

14. Fisher ER, Anderson S, Redmond C, Fisher B. Pathologic findings from the National Surgical Adjuvant Breast Project protocol B-06. 10-year pathologic and clinical prognostic discriminants. Cancer 1993; 71(8): 2507-2514.

15. Fisher ER, Redmond C, Fisher B. Prognostic factors in NSABP studies of women with node-negative breast cancer. National Surgical Adjuvant Breast and Bowel Project. J Natl Cancer Inst Monogr 1992; (11): 151-158.

16. Lippman ME. Selecting initial therapy for invasive breast cancer. Cancer 1987; 60(Suppl 8): 2050-2053 (review).

17. Margolese RG. Surgical considerations for invasive breast cancer. Surg Clin North Am 1999; 79(5): 1031-1046 (review).

18. Paik S, Hazan R, Fisher ER, Sass RE, Fisher B, Redmond C, Schlessinger J, Lippman ME, King CR. Pathologic findings from the National Surgical Adjuvant Breast and Bowel Project: prognostic significance of erbB-2 protein overexpression in primary breast cancer. $J$ Clin Oncol 1990; 8(1): 103-112.

19. Lasry JC, Margolese RG. Fear of recurrence, breastconserving surgery, and the trade-off hypothesis. Cancer 1992; 69(8): 2111-2115.

20. Posner MC, Wolmark N. Indications for breast-preserving surgery and adjuvant therapy in early breast cancer. Int Surg 1994; 79(1): 43-47 (review).

21. Taghian AG, Bryant J, Anderson S, Deutsch M, Mamounas E, Wolmark N, Fisher B. Pattern of regional failure in patients with breast cancer treated by lumpectomy, breast radiation \pm chemotherapy and/or tamoxifen with no regional radiation: results from 10 NSABP randomized trials. Int J Radiat Oncol Biol Phys 2003; 57(2 Suppl): S168.

\section{Randomized-controlled trial of conservation therapy for breast cancer by the Scottish Cancer Trials Breast Group}

\author{
Coordinating group: Scottish Cancer Trials Breast \\ Group \\ Objective: To determine whether, when primary \\ breast cancer is treated by local excision supported
}


by systemic therapy appropriate to the ER status of the tumour, local radiotherapy can be avoided.

\section{Summary}

Accrual

- Accrual total: 585

- Accrual period: 1985-1991.

\section{Inclusion}

Patients aged $<70$ years with primary breast cancers of $4 \mathrm{~cm}$ or less.

\section{Exclusion}

Patients over 70 years, patients with tumours over $4 \mathrm{~cm}$, patients with fixation of the primary tumour, patients with involved axillary nodes. Premenopausal women with involved axillary nodes were not involved as they were enrolled in the Scottish adjuvant trial of chemotherapy vs. ovarian ablation. Patients with secondary tumour in the same or opposite breast, those with a history of previous invasive cancer at any site, or those with any medical or other factors contraindicating adherence to the protocol.

\section{Treatment}

Local excision of the tumour to $1 \mathrm{~cm}$ margin confirmed by histological examination of the specimen and an axillary lymph node clearance or sample, all patients received systemic therapy with oral tamoxifen $20 \mathrm{mg}$ daily or six 3-weekly intravenous bolus injections of cyclophosphamide $600 \mathrm{mg}$, methotrexate $50 \mathrm{mg}$ and fluorouracil $600 \mathrm{mg}$ per $\mathrm{m}^{2}$, depending on the ER status of the primary tumour. Patients were then randomly allocated to post-operative radical radiotherapy (50 Gy to the breast with boost to the tumour bed in 20-25 daily fractions by iridium implant of 20-30 Gy or by electron or orthovoltage external beam irradiation) or to no further local treatment.

\section{Follow-up}

The median follow-up of living patients was 5.7 years. Follow-up included annual mammography, annual updates of progress and analysis of hospital records.

\section{Primary end point}

Survival, DFS.

\section{Results}

6 years: In the primary analysis, there was no significant difference in overall survival rates between the two groups. But DFS rates did show a significant difference, with fewer patients who had undergone radiotherapy having fewer loco-regional relapses. The loco-regional relapse rates were $28.6 \%$ for those who had not received radiotherapy compared to $6.2 \%$ for those who had. The relapse rate in the ipsilateral breast was $24.5 \%$ in the non-irradiated group and 5.8 following radiation.

The loco-regional relapse rate was unrelated to the tumour size or patient's menstrual status. It was higher in non-irradiated patients who had residual disease in axillary nodes who had not received additional treatment.

These results show that there is a benefit from radiotherapy regardless of ER status. These initial results show that following local excision, radiotherapy to the residual breast tissue is advisable even when another appropriate adjuvant systemic therapy is given.

\section{Further reading}

1. Forrest AP, Stewart HJ, Everington D, Prescott RJ, McArdle CS, Harnett AN, Smith DC, George WD. Randomised controlled trial of conservation therapy for breast cancer: 6-year analysis of the Scottish trial. Scottish Cancer Trials Breast Group. Lancet 1996; 348(9029): 708-713.

2. Vihn-Hung, V, Verschraegen C. Breast-conserving therapy with or without radiotherapy: pooled analysis for risks of ipsilateral breast tumor recurrence and mortality. J Natl Cancer Inst 2004; 96: 115-121. 